\title{
FORMAÇÃO E ATUAÇÃO PROFISSIONAL NO CONTEXTO DO PROGRAMA ESPORTE E LAZER DA CIDADE EM UBÁ, MINAS GERAIS $^{75}$
}

João Paulo Fernandes Soares

Universidade Federal de Juiz de Fora, Governador Valadares, Minas Gerais, Brasil

\author{
Aline Laila Gomes \\ Universidade Federal de Juiz de Fora, Juiz de Fora, Minas Gerias, Brasil \\ Ludmila Mourão \\ Universidade Federal de Juiz de Fora, Juiz de Fora, Minas Gerias, Brasil \\ Susana América Ferreira \\ Universidade Federal de Juiz de Fora, Juiz de Fora, Minas Gerias, Brasil \\ Letícia Moreira \\ Universidade Federal de Juiz de Fora, Juiz de Fora, Minas Gerias, Brasil
}

\begin{abstract}
Resumo
Este estudo busca identificar os saberes mobilizados na atuação profissional no Programa Esporte e Lazer da Cidade (PELC), no município de Ubá/MG. O método de pesquisa foi o estudo de caso. As técnicas de coleta de dados foram um questionário e entrevistas individuais, aplicados a um grupo de 12 agentes sociais e 3 coordenadoras do PELC, respectivamente. Os agentes sociais e coordenadoras ressaltaram que os saberes predominantemente mobilizados são os experienciais, oriundos de vivências anteriores ao curso de graduação, em que os conteúdos físicos e esportivos foram predominantes. Destacase a necessidade de ampliar e acionar outros saberes científicos e investir na formação continuada dos profissionais que atuam no campo das políticas públicas de esporte e lazer.
\end{abstract}

Palavras-chave: Atividades de Lazer. Políticas Públicas. Formação Profissional.

\section{Introdução}

É crescente o processo de reflexão, discussão e análise no campo dos estudos do Lazer e das temáticas relacionadas às Políticas Públicas de esporte e lazer. No campo acadêmico, podem-se identificar programas de pós-graduação em nível nacional e internacional que têm o Lazer como temática de investigação (GOMES et al., 2012).

${ }^{75}$ Este artigo é resultante de um projeto de iniciação científica realizado no contexto do Programa Esporte e Lazer da Cidade no município de Ubá e foi apoiado financeiramente pela Faculdade Governador Ozanam Coelho - FAGOC. Este trabalho contou ainda com o apoio institucional do Programa de Pós-Graduação Stricto Sensu em Educação Física - Associação UFV/UFJF. 
Observa-se um aumento considerável no número de publicações científicas que tratam de temáticas ligadas às Políticas Públicas de Lazer e seus impactos, bem como de pesquisas financiadas por órgãos de fomento de instituições públicas e privadas, a fim de mapear essa realidade brasileira ${ }^{76}$.

No entanto, percebem-se algumas lacunas no que se refere às investigações sobre os processos de formação e atuação profissional no campo das políticas públicas de esporte e lazer que priorizem as visões e experiências dos sujeitos que atuam nos mais variados postos de intervenção junto à população beneficiária dessas ações governamentais.

Paralelamente a essas discussões acadêmicas, o que se percebe, em linhas gerais, é um aumento considerável nas demandas da população no que se refere ao acesso a equipamentos e serviços ligados às vivências esportivas e de lazer, que figuram como um direito individual garantido pela legislação (MELO; PERES, 2005).

Nesse sentido, o Programa Esporte e Lazer da Cidade (PELC) apresenta-se como importante política pública governamental no processo de democratização e garantia do direito de acesso ao lazer, mesmo havendo problemas na abrangência e universalização dessas ações (ALMEIDA et al., 2014).

No que se refere à produção acadêmica sobre o PELC, aspectos ligados à formação e atuação profissional no cotidiano dos programas não figuram como sendo as temáticas mais pesquisadas. Estas se configuram como as que priorizam aspectos ligados aos resultados alcançados, sua eficiência e eficácia, dentre outros fatores estruturais (EWERTON, 2010).

Nesse sentido, este trabalho vai ao encontro da necessidade de compreensão e análise de aspectos relevantes da implantação e do desenvolvimento de um programa de esporte e lazer - neste caso, o Programa Esporte e Lazer da Cidade (PELC) - em que se buscou mapear os saberes que são acionados na atuação profissional das coordenadoras e agentes sociais no contexto do PELC. Tal entendimento se faz primordial na reflexão sobre a formação dos quadros profissionais que atuam em programas e projetos sociais de lazer.

\section{Lazer como direito social e o Programa Esporte e Lazer da Cidade}

O conceito de Políticas Públicas que será aqui utilizado à guisa de análise pode ser explicitado como as formas de intervenção do Estado com o objetivo de assegurar e garantir direitos, sejam eles civis, políticos e/ou sociais (CUNHA; CUNHA, 2002).

Com a promulgação da Constituição Federal de 1988, o lazer ganha status de um direito social, cabendo ao Estado efetivá-lo por meio da elaboração de Políticas Públicas. Nesse sentido, tais direitos sociais têm também o objetivo de reduzir as desigualdades geradas pelo sistema capitalista e garantir um mínimo de bem-estar para todos os indivíduos (MUNHOZ, 2008).

Entendendo a prática esportiva e a vivência do lazer como direitos sociais e considerando o aumento da demanda por ações e projetos sociais de inclusão social nesse setor de direitos (RODRIGUES; DARIDO; PAES, 2013), o Ministério do Esporte, por intermédio da Secretaria Nacional de Desenvolvimento do Esporte e do Lazer (SNDEL), cria, em 2003, o Programa Esporte e Lazer da Cidade (PELC), que tem como objetivos centrais

76

Dentre as iniciativas, podemos citar o Centro de Desenvolvimento do Esporte Recreativo e do Lazer (CEDES), vinculado ao Ministério de Esporte, que tem como uma das metas fomentar, incentivar e divulgar novos estudos científicos acerca da temática "lazer". 
democratizar e universalizar o acesso aos conteúdos culturais do lazer, integrando suas ações às demais políticas públicas, favorecendo o desenvolvimento humano e a inclusão social, contribuindo para exercício pleno da cidadania (ALMEIDA et al., 2014; TELLES, 1999).

A partir dessas orientações e princípios, o PELC foi implantado em novembro de 2006 no município de $\mathrm{Ubá} / \mathrm{MG}^{77}$ e passou por dois períodos de renovação, permanecendo em atividade até 2011. Nessas três edições, atuaram no Programa aproximadamente quarenta de cinco profissionais, das mais diversas formações, inclusive pessoas sem uma formação acadêmica específica. Entretanto, os profissionais e estagiários do curso de Educação Física sempre representaram a maioria na ocupação desses cargos.

Na segunda edição (2008/2009), quando o Programa era gerenciado por uma entidade filantrópica do município, foi atendido um total de 2.424 beneficiários, divididos por faixas etárias, em que 1.000 indivíduos estavam na faixa etária de 7 a 17 anos; 720, de 18 a 24 anos; 350 , de 25 a 59 anos; e 354 com 60 anos ou mais ${ }^{78}$.

Em sua terceira edição (2010/2011), as ações dos núcleos do PELC Ubá foram transferidas para a gestão da Prefeitura Municipal de Ubá, por meio da Divisão de Esporte, atualmente vinculada à Secretaria de Educação. Nessa edição, as atividades foram desenvolvidas em dois núcleos, e foi atendido um total de 1.165 beneficiários, sendo 658 indivíduos na faixa etária de 7 a 17 anos; 47, de 18 a 24; 249, de 25 a 59; e 211 com 60 anos ou mais.

As atividades desenvolvidas nas oficinas foram compostas por práticas corporais como capoeira, dança, esportes coletivos como voleibol, futebol e handebol, caminhadas, exercícios de alongamento e ginástica localizada, divididas por faixas etárias, visto que algumas vivências eram direcionadas a grupos etários específicos, como a caminhada, a ginástica localizada e os exercícios de alongamento, ficando restritos ao público adulto e aos idosos.

Entendendo que as políticas públicas necessitam de diálogo sobre sua efetividade, especificamente na atuação profissional em programas e projetos sociais de esporte e lazer, e tendo em vista a sua relevância no cenário nacional e local, fez-se necessário ir a campo a fim de problematizar a atuação dos profissionais envolvidos nesse campo de atuação.

Assim, refletir sobre aspectos da formação e da atuação desses profissionais é uma das finalidades do presente estudo, na medida em que suas trajetórias interferem sobremaneira em sua prática pedagógica junto ao público atendido pela política pública, ficando assim evidenciadas as possibilidades e a necessidade de qualificação e formação continuada dos quadros de pessoal que atuam no contexto das políticas públicas de esporte e lazer (MARCELLINO, 2007).

Outro ponto norteador da análise é a pretensa necessidade de coerência entre as diretrizes e propostas pedagógicas institucionais e a atuação dos profissionais envolvidos na efetivação do Programa.

77 O município de Ubá fica localizado na Zona da Mata mineira, a $297 \mathrm{~km}$ da capital, Belo Horizonte, e a 110 km de Juiz de Fora. A população é de 101.519 habitantes e tem como principal atividade econômica a produção moveleira (IBGE, 2010).

${ }^{78}$ Esses dados são oriundos da análise documental dos relatórios finais disponibilizados pela Coordenação Geral do PELC/Ubá aos pesquisadores. 


\section{Formação e atuação profissional no campo do lazer}

Atualmente, são crescentes as possibilidades de intervenção profissional no campo do lazer. Dentre elas, podemos citar as intervenções em Programas e Projetos Sociais de Esporte e Lazer.

Entretanto, segundo Isayama (2005), antes de entender a formação e atuação no campo do Lazer, é necessário compreendê-lo em sua multidisciplinariedade, ou seja, como um elemento que agrega possibilidades de atuação de diferentes áreas de conhecimento. Destacase, pois, o fato de o profissional de lazer necessitar de referencial teórico que balize sua intervenção pedagógica.

Nesse sentido, Gomes (2000) ainda esclarece que o profissional de Lazer necessita de uma formação densa, a qual, além de relacionar a teoria e a prática, deve estar comprometida com a cultura e com o objetivo de dar significado às práticas, transformando a realidade social a partir de visões críticas e questionamentos, melhorando a qualidade de vida dos indivíduos; sem perder de vista que a atuação no campo do Lazer não pode ser tratada de forma isolada de outras questões sociais (MARCELINO, 2001).

Parte dos recursos humanos que atuam na área do lazer é formada em cursos de graduação em Educação Física, Turismo, Pedagogia, Psicologia, Sociologia, dentre outras áreas, sendo estas as mais proeminentes nesse campo ${ }^{79}$. Contudo, também atuam nessa área indivíduos sem uma formação acadêmica específica, os chamados "leigos".

Em texto recente sobre os perfis dos profissionais que atuam no PELC, Almeida et al. (2014) expõem a multiplicidade e diversidade das formações no contexto desse programa e a complexidade em realizar generalizações em termos de conteúdos em nível nacional. Além disso, as autoras apontam que são necessárias mais investigações, assim como o cruzamento de dados, na busca de um perfil desse profissional. No entanto, segundo as autoras:

Conhecer o seu perfil tem implicações na qualificação de estratégias para sua formação continuada e, por conseguinte, possibilita elementos para o melhor delineamento do programa social, no que concerne ao tipo de ação/intervenção realizada em comunidades. (ALMEIDA, et al. 2014, p. 216).

Analisando o perfil de formação da equipe que atuou na gestão do PELC da cidade de Ubá (2010/2011), a qual foi investigada neste estudo, verificamos que o grupo era formado por quinze participantes, ocupando as seguintes funções: uma coordenadora geral, dois coordenadores de núcleo e doze agentes sociais. Os que ocupavam os cargos de coordenação possuíam formação superior em Educação Física; já os agentes eram graduandos nessa mesma área de formação ${ }^{80}$.

Ao trazer alguns elementos sobre a formação de profissionais de Educação Física que atuam no campo do Lazer, Marcellino (2007) aponta que as disciplinas ligadas ao Lazer foram sendo incluídas nos cursos de Educação Física, em que predominavam a

${ }^{79}$ Quando falamos da formação dos profissionais do lazer, podemos distinguir seis categorias possíveis: cursos livres de curta duração, formação de nível superior específica, inserção de habilitações em cursos de nível superior, pós-graduação stricto sensu diversificada com linhas de pesquisa específicas, pós-graduação lato senso e MBA (MARCELLINO, 2007, p.15).

${ }^{80}$ A discussão sobre o perfil de formação dos profissionais do PELC Ubá e os desdobramentos deste em suas atuações profissionais serão retomados em momento posterior deste texto. 
instrumentalização dos futuros profissionais para atuarem de forma restrita a brincadeiras, jogos e outros conteúdos de caráter ocupacional, expondo uma visão reducionista dessas atuações profissionais.

Corroborando com estas afirmações, Isayama (2003) expõe:

Ainda prevalece um entendimento de que o profissional que atua com lazer deve levar as pessoas a esquecerem seus problemas cotidianos (...) neste contexto, sua atuação se restringe à organização de jogos e brincadeiras que incentivem o agrupamento das pessoas, ou na animação de festas e bailes. (p.64).

A fim de elucidar alguns pontos dessa investigação, cabe expor que, com relação aos saberes que alicerçam a formação dos profissionais, toma-se como base a categoria "saberes docentes" (TARDIF, 2002). Esta expõe a pluralidade de saberes utilizada na prática docente, voltados tanto no seu processo de formação profissional, quanto em suas experiências de vida e do cotidiano docente.

Nesse sentido, os saberes profissionais são aqueles que se constituem em conhecimentos transmitidos e adquiridos nas instituições de ensino superior, que formam professores e profissionais de diversas áreas de conhecimento; os saberes disciplinares correspondem a diversos campos do conhecimento, são definidos socialmente e independem do curso superior de formação; já os saberes curriculares correspondem aos discursos, objetivos, conteúdos, métodos por meio dos quais a instituição escolar categoriza e apresenta os saberes sociais por ela definidos e selecionados como modelos da cultura erudita e de formação para a cultura erudita; e, por fim, os saberes experienciais ou práticos dizem respeito aos saberes específicos, ou seja, aqueles adquiridos anteriormente e que, embora não provenham de formação acadêmica específica, são utilizados na prática docente. Estes são definidos por Tardif (2002, p. 49) como:

[...] o conjunto de saberes atualizados, adquiridos e necessários no âmbito da prática docente e que não provêm das instituições formais nem dos currículos. Estes saberes não se encontram sistematizados em doutrinas ou teorias. São saberes práticos [...] Eles se constituem, por assim dizer, na cultura docente em ação.

Dessa forma, Tardif (2002) conclui que tais saberes brotam da experiência e são por ela validados.

A categoria saberes docentes será utilizada à guisa de análise para o entendimento dos saberes mobilizados pelos profissionais do Lazer em sua atuação, por entender que esta configura-se como prática pedagógica, diferenciada do universo escolar, embora apresente compromissos pedagógicos e políticos semelhantes (FIQUEIREDO; ALMEIDA, 2010; MELO, 1999; 2010).

Portanto, tal categoria irá nortear as análises realizadas neste estudo no que diz respeito à atuação das coordenadoras e agentes sociais no contexto do PELC.

\section{Percurso Metodológico}

Este estudo de caráter qualitativo teve como delineamento o método de estudo de caso (RICHARDSON, 2008) e, como foco de análise, o Programa Esporte e Lazer da Cidade, no município de Ubá, com o recorte nos aspectos da formação e da atuação profissional, que visou compreender os saberes mobilizados em suas práticas no contexto desse Programa. 
No processo de pesquisa, foi realizada também uma consulta aos documentos oficiais do PELC em nível nacional ${ }^{81}$ e aos relatórios finais das gestões do PELC da cidade de Ubá, disponibilizados pela coordenação geral do Programa aos pesquisadores.

O grupo de informantes foi composto por quinze indivíduos: uma coordenadora geral, duas coordenadoras de núcleo e doze agentes sociais, de ambos os gêneros, atuantes no PELC na gestão 2010/2011. Os dados da pesquisa foram coletados no período de maio a junho de 2010. Os procedimentos de pesquisa seguiram a legislação vigente sobre pesquisas com seres humanos ${ }^{82}$.

$\mathrm{Na}$ pesquisa de campo, foram utilizados, como técnicas de coleta de dados, um questionário, aplicado a doze agentes sociais, e um roteiro de entrevista individual, realizada com as três coordenadoras.

O questionário foi aplicado em duas reuniões da formação em serviços orientadas pelas coordenadoras. Tal técnica permitiu que os informantes pudessem redigir suas impressões acerca de sua atuação profissional.

As entrevistas com as coordenadoras foram individuais e em local público, adequados a tal fim e com prévio agendamento. Tais entrevistas foram registradas em áudio, com autorização prévia dos participantes, e sua transcrição, na íntegra, foi entregue aos informantes para a validação das informações e assinatura dos termos de consentimento livre e esclarecido (TCLE).

Na fase de análise dos dados, foi utilizada a técnica de Análise de Conteúdo, proposta por Bardin (2011), em que foi realizado o processo de categorização das narrativas. Tais dados empíricos foram posteriormente cotejados com a bibliografia pertinente, a fim de realizar a análise das categorias nativas, em confronto com as categorias analíticas.

\section{Resultados e discussão}

A categoria abordada na análise dos dados foi a Formação e Atuação Profissional no PELC, que gerou três subcategorias - a saber: Capacitação profissional do Ministério do Esporte / Formação profissional no curso superior de Educação Física / Saberes mobilizados na atuação profissional -, as quais foram confrontadas com as categorias nativas que emergiram dos discursos das coordenadoras, a partir das transcrições das entrevistas e dos dados coletados via questionários. Estas representaram aspectos relevantes das visões desses sujeitos sobre as categorias analíticas utilizadas no estudo (BARDIN, 2011).

A partir da subcategoria Capacitação Profissional do Ministério do Esporte, buscou-se balizar a análise da política nacional de formação dos profissionais que atuam no Programa, que tem como visão o fato de esses profissionais serem os responsáveis diretos pela concretização dos conteúdos culturais do lazer e do esporte nas comunidades beneficiadas pelo PELC.

A formação institucional dos trabalhadores do lazer no PELC é realizada pelo Ministério do Esporte e se constitui em três módulos pontuais e um contínuo. São eles: Módulos de formação: introdutório, aprofundamento e avaliação. A outra vertente de formação diz respeito à formação em serviços, que deve ser realizada continuamente pelos coordenadores

\footnotetext{
${ }^{81}$ Mais informações sobre o PELC podem ser obtidas no site: www.esporte.gov.br/snelis/esporteLazer/.

${ }^{82}$ Tal pesquisa está de acordo com os princípios éticos norteadores da Resolução 196/96, do Conselho Nacional de Saúde, que dispõe sobre a ética na pesquisa com seres humanos.
} 
dos núcleos, visando ao aprofundamento dos saberes de que cada agente necessita para sua intervenção.

Nesse aspecto, os dados do questionário revelaram que os agentes sociais entendem como relevantes os módulos de formação desenvolvidos pelo Ministério do Esporte, apesar das críticas apontadas ao conteúdo prático reduzido desses módulos. Verifica-se que os agentes necessitam de modelos práticos sobre como intervir, que atividades propor, como transformar as teorias tratadas em ações pedagógicas com seus alunos. Nesse sentido, levantamos pistas de que pode existir um descompasso entre as necessidades dos agentes e as premissas dos gestores para embasar as ações de intervenção desses agentes.

Os cursos de formação do PELC contemplam os saberes curriculares, utilizando-se do que a sociedade já consolidou pelos saberes experienciais com o objetivo de sistematizar finalidades e métodos. Os autores criticam o tempo de duração reduzido - trinta e duas horas cada - dos dois módulos de capacitação do PELC (FIGUEIREDO; ALMEIDA, 2010; ALMEIDA et al., 2014).

Um ponto crítico apontado foi a formação em serviços ${ }^{83}$. Dez dos doze agentes relataram problemas no processo, como a inexistência de ações e o tempo reduzido dos módulos de formação. Tal panorama é preocupante, pois a formação em serviços é central no processo de capacitação, durante o qual tais agentes poderiam compartilhar as limitações dos aspectos teóricos e práticos de suas intervenções e buscar, coletivamente, um redirecionamento das ações pedagógicas no PELC, além do incentivo à troca de saberes.

Um dos pontos relevantes identificados foi o conhecimento que os agentes sociais e as coordenadoras tinham sobre a temática das políticas públicas de esporte e Lazer. Treze dos quinze informantes abordados demonstraram conhecimento sobre o conceito de políticas públicas, identificando-as como políticas de Estado, traduzidas em projetos sociais e ações governamentais direcionadas para grupos específicos da sociedade, em geral, sujeitos que vivenciam diversas restrições no acesso ao lazer.

Outro ponto questionado foi o conceito de lazer utilizado nas intervenções profissionais. Nessa questão, os entrevistados tiveram a liberdade de marcar mais de uma opção no questionário, a fim de formar um quadro do conceito que baliza as ações. O conceito de Lazer que emergiu dessa análise aproxima-se do conceito utilizado por Gomes (2008), que o compreende como:

Uma dimensão da cultura caracterizada pela vivência lúdica de manifestações culturais no tempo/espaço conquistado ou disponível. Tem como finalidade o "desfrute" da experiência vivida cultural e socialmente. Trata-se de uma necessidade humana, direito social e possibilidade de produção cultural. É um fenômeno dialético. (p. 44).

As opções mais assinaladas associavam o lazer a atividades praticadas no tempo disponível, assim como àquelas que buscam a melhoria da saúde da população. Nesse aspecto, cabe ressaltar que, apesar de os informantes conhecerem os objetivos do PELC, notase que a associação com a saúde demostra um redirecionamento dos princípios do PELC.

\footnotetext{
${ }^{83}$ Trata-se de uma formação continuada durante todo o período da vigência do convênio com o Ministério do Esporte. Tais intervenções, que ficam a cargo das coordenações, visam ampliar os conhecimentos dos agentes sociais sobre a intervenção no campo do Lazer, por meio de atividades sistemáticas em formato de oficinas e cursos temáticos.
} 
Sobre esse ponto, podemos destacar que dois dos coordenadores de núcleo e a coordenadora geral do Programa, ao serem questionados se o PELC/Ubá modificaria de alguma forma a percepção das pessoas atendidas sobre o lazer, responderam afirmativamente, justificando suas respostas com os seguintes depoimentos:

Olha, com certeza o PELC veio pra poder fazer uma transformação no sentido de que as pessoas, por exemplo, antes de fazer as atividades no PELC, elas ficavam dentro de casa, vendo uma televisão; isso foi relato deles próprios. (Informante 3 , coordenadora)

Nossa! Totalmente sim. As pessoas achavam que lazer é ficar à toa e olhar para o tempo. (Informante 2, coordenadora)

Já a primeira entrevistada tem um posicionamento diferente:

Olha! Na verdade, eu não sei nem se eles têm alguma percepção de lazer, não sei o que passa em nível de percepção. Nós nunca fizemos nenhum trabalho ou aplicação de questionário pra tentar levantar esse perfil ou diagnosticar isso. (Informante 1, coordenadora)

As falas vão ao encontro de uma visão de lazer que privilegia a mobilização física, ou seja, os conteúdos físicos esportivos, sem observar, de forma ampla, a complexidade das vivências lúdicas de lazer. Tais posicionamentos revelam uma visão restrita do lazer, que deveria, em primeira instância, ser considerada no processo de capacitação institucional.

Outro ponto de análise foi o questionamento sobre o conhecimento que tais agentes sociais têm acerca dos objetivos e das diretrizes do PELC. Do grupo de doze agentes, onze admitiram conhecer os objetivos do PELC, entretanto, no que diz respeito às diretrizes do programa, houve uma inversão: os doze assinalaram a opção "não", ou seja, desconhecem as diretrizes nacionais do Programa.

As coordenadoras, ao serem questionadas em que medida a atuação realizada pelos agentes sociais e coordenadores nos bairros atende às diretrizes e aos objetivos do PELC, assim se manifestaram:

Acredito que atende, porque o projeto e o plano básico dão condições para esse atendimento; o que difere nisso são os espaços físicos, que a maioria dos bairros não tem. Então, os coordenadores e os agentes, acompanham a metodologia de trabalho, o que foi colocado no projeto. $O$ que se pode fazer dentro do limite a gente faz o que é possível. Não se faz mais pela falta de espaço. Existe uma verba que é limitada, é já destinada para tudo, então não tem muito que fazer, tem que seguir o plano. E, dentro da metodologia do projeto, nós estamos coerentes. (Informante 1, coordenadora).

Olha! Eu sou suspeita em falar, porque eu acho que o trabalho dos meus agentes é perfeito; eles trabalham com muito amor, com muita garra, muita responsabilidade $e$, onde eles passam, eles são carismáticos, eles deixam marcas profundas. (Informante 2, coordenadora).

Não, não atende, porque, primeiro, o material que o PELC fornece pra gente não é de boa qualidade e nós não temos espaço físico adequado. Falta estrutura pra que se possa realizar o que está no papel. (Informante 3, coordenadora) 
Nessas falas, as categorias "espaço" e "material didático" foram marcantes, uma vez que diversas limitações nesses quesitos interferem de diversas formas na concretização do Programa. Os saberes acionados pelos agentes para redirecionar suas intervenções a partir de algumas limitações são relevantes nas falas, contudo, emergem de forma limitada nas capacitações do Programa, segundo os informantes.

Dessa forma, a categoria "desconhecimento das diretrizes do PELC" foi marcante nos dados obtidos dos agentes, bem como das coordenadoras, os quais caminham na direção de uma limitação na formação institucional no módulo introdutório, bem como da formação em serviços, que tem como um de seus princípios a constante difusão das diretrizes, objetivos e a proposta didático-metodológica do PELC, durante a vigência do Programa.

Sobre a subcategoria "formação profissional", especificamente no curso superior de Educação Física, todos os coordenadores e agentes sociais do PELC/Ubá envolvidos nesta pesquisa são graduados e graduandos em Educação Física, respectivamente, sendo que os primeiros possuem pós-graduação lato sensu em temáticas ligadas aos aspectos biodinâmicos do movimento humano.

Em estudo que objetivava mapear um perfil de formação profissional, Isayama (2005) pôde constatar que parte dos profissionais das Secretarias Municipais de Esporte de municípios próximos a Belo Horizonte é graduada em Educação Física. Segundo o autor, se por um lado a formação desses profissionais tem como base a atualização de sua formação inicial, por outro se entende a formação como um processo contínuo, valorizando a aquisição de experiência e o trabalho profissional (ISAYAMA, 2005).

Em estudo recente, Gomes e Isayama (2013) buscaram elucidar as diferenciações nos conteúdos ministrados nas disciplinas ligadas ao Lazer nos cursos de licenciatura e bacharelado em Educação Física. A partir desses achados, não foi possível perceber diferenciações consistentes no trabalho dessas duas áreas de formação profissional, no entanto tais saberes foram priorizados em cursos de bacharelado em Educação Física.

Nesse sentido, os agentes sociais revelaram que foram trabalhados conhecimentos sobre a atuação profissional no campo do Lazer em pelo menos duas disciplinas da graduação ${ }^{84}$. No entanto, a carga horária elevada de disciplinas esportivas de certa forma direciona o trabalho deles para os conteúdos físicos esportivos, por se sentirem mais "seguros" ao tratar esse conhecimento.

Outro ponto abordado foram as atividades trabalhadas nas oficinas, a saber: caminhada orientada, capoeira, ginástica, esportes coletivos como o futebol e o voleibol, xadrez, damas e atividades manuais como pintura e desenho, conforme expõem duas informantes da pesquisa:

Olha, nós estamos com alongamento, futsal, handebol, voleibol e basquete também, os esportes coletivos. Mais a maior das oficinas que é realizada é o alongamento. (Informante 2, coordenadora)

Dentro do possível e do que o bairro oferece, hoje tem teatro, dança. Dentro da dança, nós temos axé, tem dança de salão, tem o funk, tem o hip hop, as oficinas de esporte ou de desporto de uma forma geral, handebol, basquete, voleibol, futsal, futebol. As atividades de alongamento e caminhada orientada tanto pra adolescentes, mas principalmente pra terceira idade, que é um público muito

\footnotetext{
${ }^{84}$ Todos os agentes sociais cursavam a licenciatura em Educação Física em uma instituição particular situada no município de Ubá.
} 
presente também nas aulas de dança. É um público bem interessante. (Informante 1, coordenadora)

De forma geral, os saberes disciplinares são utilizados durante a intervenção e, principalmente, no período de planejamento das ações nos bairros (TARDIF, 2002). No entanto, apenas uma parte dos saberes adquiridos no curso superior, sobre os conteúdos culturais do lazer e vivências corporais, é utilizada no cotidiano dos núcleos.

Questionados sobre suas preferências em relação aos conteúdos a serem trabalhados, os agentes e coordenadores apontaram para uma intensa utilização dos saberes experienciais, que são mobilizados a partir das vivências motoras individuais dos agentes antes do curso superior de formação.

Tais saberes experienciais são relevantes, na medida em que exprimem um processo de revisão e ampliação de conceitos teóricos ao confrontar as perspectivas com a realidade pedagógica. Cabe ressaltar que uma intervenção profissional mobilizada prioritariamente em saberes experienciais torna-se insuficiente, já que outros saberes oriundos do universo acadêmico são omitidos aos alunos das oficinas do PELC. Não cabe priorizar os saberes e sim ampliá-los, em um processo constante de trocas entre si.

\section{Considerações finais}

$\mathrm{Na}$ atualidade brasileira, o Programa Esporte e Lazer da Cidade (PELC) se faz relevante na consolidação do esporte e do lazer como direitos sociais. Os resultados alcançados pelo Programa vão nessa direção, porém o investimento na qualificação e capacitação dos profissionais envolvidos, bem como em ações de monitoramento e na avaliação, se fazem necessários, atentando para a realidade dos municípios em que a política pública ocorre.

O PELC/Ubá corrobora com tal processo, na medida em que o conjunto das ações e os resultados quantitativos e qualitativos revelam um avanço no que se refere à disponibilização de vivência dos interesses culturais do Lazer, mesmo que com direcionamento aos interesses físico-esportivos.

A formação e a capacitação continuada dos recursos humanos se mostraram adequadas até certo ponto, apresentando algumas lacunas que podem ser amenizadas com um efetivo processo de formação em serviços de forma contínua, com vistas a dar retornos sobre a intervenção pedagógica realizada pelos agentes sociais em seus núcleos. Apesar de os saberes prioritários mobilizados nos momentos de intervenção serem experienciais, faz-se relevante problematizar esse processo e compreender até que ponto os cursos de formação superior estão formandos profissionais para a atuação no contexto das Politicas Públicas de Esporte e Lazer.

Nesse sentido, este estudo traz reflexões sobre o processo de formação e atuação de profissionais no campo do Lazer. Cabe ensejar novas pesquisas para ampliar e qualificar o debate sobre tão relevante e atual temática.

\section{Referências Bibliográficas}

ALMEIDA, D. F. et al. Trabalhadores do lazer do programa esporte e lazer da cidade: uma aproximação à definição de um perfil. Movimento, Porto Alegre, v. 20, n. 01, jan./mar., 2014. 
ALMEIDA, D. F. Estatização, políticas sociais e lazer no Brasil. Licere, Belo Horizonte, UFMG, v. 13, n. 4, out. 2010.

BARDIN, L. Análise de conteúdo. 6. ed. Lisboa: Edições 70, 2011.

BRASIL. Manual de orientações para implementação do Programa Esporte e Lazer da Cidade. Brasília: Ministério do Esporte, 2008. Disponível em: http://www2.esporte.gov.br/arquivos/snelis/esporteLazer/diretrizesPELCEdital2013.pdf. Acesso em: 20 jun. 2015.

CUNHA, E. P.; CUNHA, E. S. M. Políticas públicas sociais. In: CARVALHO, Alysson et al. Políticas públicas. Belo Horizonte: Editora UFMG, 2002.

EWERTON, A. N. Análise da formação profissional no Programa Esporte e Lazer da Cidade (PELC): o olhar dos agentes sociais. Dissertação de mestrado. Belo Horizonte: UFMG, 2010.

GOMES, C. L. et al. Políticas Públicas de Lazer: pesquisando a temática no contexto de cinco mestrados latino-americanos. Licere, Belo Horizonte, UFMG, v. 15, n. 4, dez. 2012.

GOMES, C. L. Lazer, trabalho e educação: relações históricas, questões contemporâneas. 2. ed. Belo Horizonte: UFMG, 2008.

GOMES, R. D. O.; ISAYAMA, H. F. Lazer e formação profissional: um estudo sobre licenciatura e bacharelado em educação física. Licere, Belo Horizonte, UFMG, v. 16, n. 4, dez. 2013.

FIGUEIREDO, P. O. F. de N.; ALMEIDA, D. F. de. Educação e formação dos trabalhadores do Programa Esporte e Lazer da Cidade. In: ALMEIDA et al. (Orgs.). Política, lazer e formação. Brasília: Thesaurus, 2010.

FRANÇA, T. Lazer e formação profissional. Licere, Belo Horizonte, UFMG, v. 8, n. 1, jun. 2005.

IBGE cidades. Brasil. Disponível em: <www.ibge.gov.br/cidades>. Acesso em: 15 fev. 2011.

ISAYAMA, H. F. Um olhar sobre a formação profissional no lazer. Licere, Belo Horizonte, UFMG, v. 8, n. 1, jun. 2005.

. O profissional de educação física como intelectual: atuação no âmbito do lazer. In: MARCELLINO, N. C. Formação e desenvolvimento de pessoal em lazer e esporte: para atuação em políticas públicas. Campinas: Papirus, 2003.

MARCELlinO, N. C. et al. Políticas públicas de lazer, formação e desenvolvimento de quadros: os casos de Campinas e Piracicaba. SP. 1. ed. Curitiba: Opus Print, 2007.

MARCELLINO, N. C. Lazer e esporte: políticas públicas. 2. ed. Campinas: Autores associados, 2001. 
MELO, V. A.; PERES, F. F. A cidade e o lazer: as desigualdades sócio espaciais na distribuição dos equipamentos na cidade do Rio de Janeiro e a construção de um indicador que oriente as ações em políticas públicas. Movimento, Porto Alegre, v. 11, n. 3, 2005.

MELO, V. A.; NASCIMENTO, M. A. Capacitação de animadores culturais: uma experiência na comunidade do morro do Borel. Licere, Belo Horizonte, UFMG, v. 2, n. 1. 1999.

MENDES, R.; C. JÚNIOR, C. F. F. Compreensões sobre o lazer: uma análise do Programa Esporte e Lazer da Cidade em Minas Gerais. Licere, Belo Horizonte, UFMG, v. 12, n. 3, ago. 2009.

MENICUCCI, T. Políticas Públicas de Lazer: Questões analíticas e desafios políticos. In: ISAYAMA, H.; LINHARES, M. A. (Orgs.). Sobre lazer e política: maneira de ver, maneiras de fazer. Belo Horizonte: UFMG, 2006.

MUNHOZ, V. C. C. O lazer como direito social na Prefeitura de Belo Horizonte. In: IZAYAMA, H.; LINHALES, M. A. (Orgs.). Avaliação de políticas e políticas de avaliação. Belo Horizonte: UFMG, 2008.

RICHARDSON, J. R. et al. Pesquisa social: métodos e técnicas. 3. ed. São Paulo: Atlas, 2008.

RODRIGUES, H. A.; DARIDO, S. C.; PAES, R. R. O esporte coletivo no contexto dos projetos esportivos de inclusão social: contribuições a partir referencial técnico tático e sócio educativo. Pensar a Prática, Goiânia, v. 16, n. 2, 2013.

TARDIF, M. Saberes docentes e formação profissional. Petrópolis, RJ: Vozes, 2002.

TELLES, V. L. Direitos sociais: afinal do que se trata? Belo Horizonte: ed. UFMG, 1999.

\title{
PROFESSIONAL TRAINING AND PERFORMANCE IN THE CONTEXT OF A PROGRAM FOR SPORT AND LEISURE IN UBÁ, MINAS GERAIS
}

\begin{abstract}
This case study aims at identifying the knowledge mobilized by professional performance in the Programa Esporte e Lazer da Cidade (PELC), in Uba, Minas Gerais, Brazil. The research method was the case study. As for the techniques of data collection, a questionnaire and individual interviews were applied to a group of 12 social agents and 3 PELC coordinators, respectively. All the informants stressed that the knowledge they mobilized is predominantly experiential, usually derived from previous experiences in undergraduate courses, in which physical sports were predominant. The findings of this study highlight the need to expand and trigger other scientific knowledge and invest in the continuing education of professionals working in the field of public policy for sport and leisure.
\end{abstract}

Keywords: Leisure Activities. Public Policies. Professional Training. 


\title{
FORMACIÓN PROFESIONAL Y ACTIVIDADES EN EL MARCO DE UN PROGRAMA PARA EL DEPORTE Y EL OCIO EM UBÁ, MINAS GERAIS
}

\begin{abstract}
Resumen
Este estudio tiene como objetivo identificar el conocimiento movilizado en el desempeño profesional en el Programa Esporte e lazer da Cidade (PELC) en la ciudad de Ubá, Minas Gerais. El método de investigación fue el estudio de caso. Las técnicas de recolección de datos fue un cuestionario y entrevistas, que se aplica a un grupo de 12 trabajadores sociales y 3 coordinadores del PELC, respectivamente. Los trabajadores sociales y coordinadores hicieron hincapié en que el conocimiento se movilizan predominantemente vivencial, que viene de las experiencias previas de pregrado, donde el contenido físico y los deportes eran predominantes. Destaca la necesidad de ampliar y activar otros conocimientos científicos e invertir en la formación continuada de los profesionales que trabajan en el campo de las políticas públicas para el deporte y el ocio.
\end{abstract}

Palabras clave: Ocio. Políticas Públicas. Capacitación.

Recebido em: 09/10/2013

Revisado em: 08/04/2014

Aprovado em: 25/08/2015

Endereço para correspondência:

João Paulo Fernandes Soares

joaopaulosoaresufjf@gmail.com

Campus Avançado Governador Valadares - UFJF

Avenida Dr. Raimundo Monteiro Rezende, 330 - Centro

Governador Valadares/MG - CEP 35010-177 